\title{
Options for perioperative pain management in neurosurgery
}

This article was published in the following Dove Press journal:

Journal of Pain Research

10 February 2016

Number of times this article has been viewed

\author{
Nalini Vadivelu' \\ Alice $M \mathrm{Kai}^{2}$ \\ Daniel Tran' \\ Gopal Kodumudi ${ }^{3}$ \\ Aron Legler' \\ Eugenia Ayrian ${ }^{4}$ \\ 'Department of Anesthesiology, \\ Yale University School of Medicine, \\ New Haven, CT, ${ }^{2}$ Stony Brook \\ University School of Medicine, Stony \\ Brook, NY, ${ }^{3}$ California Northstate \\ University College of Medicine, Elk \\ Grove, ${ }^{4}$ Keck School of Medicine of \\ the University of Southern California, \\ Los Angeles, CA, USA
}

\begin{abstract}
Moderate-to-severe pain following neurosurgery is common but often does not get attention and is therefore underdiagnosed and undertreated. Compounding this problem is the traditional belief that neurosurgical pain is inconsequential and even dangerous to treat. Concerns about problematic effects associated with opioid analgesics such as nausea, vomiting, oversedation, and increased intracranial pressure secondary to elevated carbon dioxide tension from respiratory depression have often led to suboptimal postoperative analgesic strategies in caring for neurosurgical patients. Neurosurgical patients may have difficulty or be incapable of communicating their need for analgesics due to neurologic deficits, which poses an additional challenge. Postoperative pain control should be a priority, because pain adversely affects recovery and patient outcomes. Inconsistent practices and the quality of current analgesic strategies for neurosurgical patients still leave room for improvement. Given the complexity of postoperative pain management for these patients, multimodal strategies are often required to optimize pain control and at the same time limit undesired side effects.
\end{abstract}

Keywords: acute pain, post surgical pain, post craniotomy analgesia

\section{Introduction}

Several neurosurgical procedures can cause postoperative pain including craniotomies for tumor resections, epilepsy surgery and craniotomies for aneurysm clipping, penetrating traumatic brain injury, and neuroradiological procedures such as arteriovenous embolization procedures and aneurysm coilings. Postoperative hematomas, elevation of intracranial pressures, cerebral infarctions, seizures, hypertension, development of air embolism, cranial nerve injury, and the development of cerebral edema and stroke can complicate the management of postoperative pain.

The management of postoperative pain following intracranial procedures has been undermanaged for numerous reasons in the past, ${ }^{1-4}$ including the apprehension that the administration of opioids can affect or hinder monitoring of the neurological examination. ${ }^{5-8}$ Opioids, which are the agents that are most frequently prescribed for moderate-to-severe pain, can cause miosis, sedation, and conceal signs of adverse intracranial emergencies. ${ }^{9}$ In addition, they can lead to respiratory depression that causes hypercapnia and increased intracerebral blood volume and can possibly progress to cerebral edema and elevated intracranial pressure. ${ }^{10}$ Therefore, it has been historically reasoned that patients' exposure to the risks of opioid administration should be minimized given the widely presumed idea that intense pain is not experienced following intracranial procedures, a belief reinforced by the fact that surgical procedures on the brain parenchyma in itself do not cause pain. ${ }^{11}$
Correspondence: Nalini Vadivelu Department of Anesthesiology, Yale University School of Medicine, 333 Cedar Street, TMP 3, New Haven, CT 06520 , USA

Tel +I 2037852802

Email nalini.vadivelu@yale.edu 
However, an increasing number of studies on adult patients suggest that pain after intracranial surgery is, as it goes, frequent, often severe, and undermanaged. ${ }^{12-14}$ Insufficient treatment of pain in other postoperative situations is associated with adverse outcomes, ${ }^{15}$ and aggressive management of pain for other conditions is now a notably prevailing practice and has become a customary standard of care. ${ }^{12}$ A recent study by Mordhorst et $\mathrm{a}^{16}$ found that within the initial 24 hours post craniotomy, $55 \%$ of patients experienced moderate-to-severe pain. These results are also consistent with findings from a pilot study by De Benedittis et al, ${ }^{17}$ which found that $60 \%$ of patients had pain postoperatively. In this review, we discuss the different modalities of pain management, and drug options, as well as their associated risks and benefits.

\section{Acute pain post craniotomy Incidence}

Incidence of pain is associated with surgical site. The highest incidence of postoperative pain occurs after subtemporal and suboccipital approaches, ${ }^{17}$ whereas patients who undergo frontal craniotomies experience less pain and require less opioid analgesics. ${ }^{18}$ This fact can be explained by the extended muscle damage from the resection of temporal and posterior cervical muscles. ${ }^{4}$

Prior to the pilot study published by De Benedittis et al in $1996,{ }^{17}$ which demonstrated that $60 \%$ of patients experienced postoperative pain; it was historically believed that craniotomies are less painful than other operations. ${ }^{19}$ The study observed that for two-thirds of these patients, the pain experienced was moderate to severe. Furthermore, pain, most often, was experienced within the first 48 hours post-procedurally. Notably, up to $32 \%$ of patients continued to feel pain past the initial 48 hours. Although pain caused by craniotomies may be less severe than pain following other procedures, there is an increasing agreement that it continues to be undermanaged in the acute recovery phase of some patients. ${ }^{3,13}$

The pain is classically described as pounding or pulsating similar to tension headaches. Less commonly, it is portrayed as a continuous and constant pain. ${ }^{20}$ The highest incidence of pain has been reported in younger and female patients ${ }^{21}$ and patients with preoperative opioid use. ${ }^{4,22}$ It has been proposed that the incidence of pain is higher in female patients than male patients, because men may have an increased awareness of health and perception of the role of pain. On the contrary, the elderly are largely believed to be comparatively tolerant of pain. ${ }^{23}$

\section{Pathogenesis}

Most patients describe the pain as predominantly superficia ${ }^{17}$ suggesting a pathogenesis that is somatic instead of visceral. It is believed to originate from soft tissue and pericranial muscle, rather than the brain tissue itself. Subtemporal and suboccipital pathways are associated with the highest incidence of pain, perhaps associated with invasive procedural stress on major muscle including the splenius capitis, temporal, and cervicis muscle tissues. The resulting pain is commonly nociceptive and is induced by the surgical incision and a reflection of the muscle structured below the scalp. ${ }^{3,13,24}$

\section{Clinical studies}

A study by Gee et $\mathrm{al}^{25}$ assessed whether there are any significant differences in preexisting pathology, including preoperative headaches, in patients undergoing craniotomies for intracranial hemorrhages, brain tumors, or epilepsy. The study found that half of the patients who had not had any preoperative headaches had severe headaches postoperatively. Of note, most of the patients who experienced headaches underwent craniotomies for epilepsy. Therefore, Gee et al reasoned that postoperatively in the acute state, the qualities of the headaches are seemingly a mixture of "site-of-injury" headaches and tension headaches on the surgical site. The quality of the headaches was comparable with posttraumatic headaches.

It is widely agreed upon that the severity of postoperative pain following a craniotomy is dependent on the manner of surgical method. For instance, procedures performed on the base of the skull, particularly those utilized for acoustic neuromas and tumors of the posterior fossa, are associated with a greater incidence of intensely painful postoperative headaches. A study by Vijayan ${ }^{26}$ demonstrated that $42 \%$ of patients prior to excision of an acoustic neuroma had no headaches or only minor headaches presurgery. Post surgery, $75 \%$ of patients reported headaches. A slow but steady improvement in pain was found in $32 \%$ of these patients with time.

Gottschalk et $\mathrm{al}^{5}$ found that postoperatively, in patients who had undergone intracranial surgery, pain was common within the first 2 days following intracranial procedures if treated solely with acetaminophen and moderate doses of opioids on an as-needed basis. Although this is not consistent with the findings of a larger retrospective study of postoperative pain immediately following surgery, ${ }^{27}$ it is consistent with the findings of previous studies conducted on a smaller scale of pain post intracranial procedure. ${ }^{13,24}$ Around two-thirds of patients reported experiencing moderate-to-severe pain 
during the duration of their hospitalization. In addition, the study reported that patients who had undergone infratentorial procedures experienced greater pain with movement and at rest relative to the patients who had undergone supratentorial procedures who were administered more nonopioid and opioid analgesics for pain management accordingly. Furthermore, the report of dissatisfaction in the analgesic management was highly associated with high levels of pain on the initial 2 days postoperatively. Although drugs ordered for pain management were on an as-need basis including opioids, analgesics, and acetaminophen, Gottschalk ${ }^{28}$ showed that there is growing evidence of the undermanagement of pain following intracranial procedures.

In another study consisting of predominantly supratentorial procedures, $56 \%$ of patients were found to experience persistent pain for 2 months following the procedure. Of these patients, half of them reported neuropathic symptoms. Notably, the incidence of persistent pain was effectively decreased by several folds via long duration of local anesthetic infiltration at the end of the procedure at the site of the surgery. ${ }^{29}$ That is to say, following intracranial procedures, perioperative pain is an expected but addressable consequence via utilization of reasonably basic and familiar techniques. ${ }^{28}$

Similarly, Hansen et $\mathrm{al}^{2}$ reported that among the 59 patients who underwent elective infratentorial or supratentorial craniotomies at the Department of Neurosurgery, Rigshospitalet, Denmark, 56\% experienced moderate-to-severe pain (numeric rating scale 4-10 on an eleven-point scale) within the initial hour postoperatively, which then decreased to $38 \%$ of the patients within 24 hours postoperatively, during which the median numeric rating scale score reported during the duration of the 24-hour study period ranged from two to four. There were no reported significant differences in the postoperative analgesic consumption or pain score when assessing for differences in sex, surgical site (supratentorial versus infratentorial), or of surgical drains. However, it was noted that the female patients who underwent infratentorial procedures reported higher scores of pain. Patients who were given steroids preoperatively reported significantly reduced pain relative to patients who were not administered any steroids $(P=0.04)$. To note, there was a low incidence of postoperative vomiting and nausea $-86 \%$ of the patients denied any nausea within the initial postoperative hour, and $78 \%$ denied any pain at the 24 -hour mark. Furthermore, the incidence of patients who reported sedation in the initial 24 hours postoperatively was $62 \%$, which decreased to $22 \%$ by the 24 -hour mark postoperatively. ${ }^{30}$ Thus, historical concerns of the adverse effects of sedation, nausea, and vomiting should be reevaluated, and a shift toward addressing the undermanagement of pain should be stressed.

\section{Pharmacological management Anticonvulsants}

Gabapentin is a new drug utilized for the postoperative pain management with a unique mechanism and antihyperalgesic uses. Numerous studies have demonstrated that perioperative administration of gabapentin diminishes pain postoperatively. Gabapentin was originally introduced in 1994 for use for partial seizures as an antiepileptic drug. It is an anticonvulsant with side effects, which are well absorbed and well tolerated following oral administration with the greatest concentration in the plasma observed in 2-3 hours. ${ }^{31,32}$ The most common adverse side effects are peripheral edema, dizziness, fatigue, drowsiness, and ataxia..$^{30,33}$

Gabapentin is an anticonvulsant with a chemical structure similar to gamma-aminobutyric acid but binds to presynaptic voltage-gated calcium channels instead of gammaaminobutyric acid receptors. It, along with the related but more potent pregabalin, has been used to treat neuropathic as well as postoperative pain following spinal surgery and has been shown to decrease opioid requirements. ${ }^{34}$

Gabapentin functions by decreasing posterior horn neuronal hyperexcitability induced by lesions. ${ }^{35}$ It is believed that the antihyperalgesic properties of gabapentin are due to its binding activity to the alpha2-delta subunit of the voltage-dependent calcium channels of dorsal horn neurons, thereby reducing the influx of calcium into nerve endings and reducing neurotransmitter release. Other postulated mechanisms propose the activity of gabapentin on monoaminergic pathways, sodium channels, the opioid system, and $N$-methyl-D-aspartate (NMDA) receptors., ${ }^{3,25,36,37}$ Türe et al ${ }^{38}$ studied the effects of gabapentin on acute postoperative pain when administered several months in advance as antiepileptic prophylaxis in patients scheduled for craniotomies for supratentorial tumor resection and found that preoperative administration of gabapentin was effective in treating acute postoperative pain but only to a small degree, as well as in decreasing postoperative analgesic consumption; however, it may contribute to delayed extubation and increase the level of sedation postoperatively.

The majority of patients who undergo craniotomies are administered corticosteroids before their procedures, mainly to decrease vasogenic edema. In addition to these effects, corticosteroids also provide effective anti-inflammatory effects via modulation of peripheral nociceptors. ${ }^{39}$ Also, corticosteroids may relieve headaches postoperatively by 
decreasing chemical meningitis triggered by the formation of the dust from bone surgically. In fact, even patients who are given corticosteroids perioperatively may also be able to tolerate greater amounts of opioids and have improved pain control due to the drug's central antiemetic effects. ${ }^{40}$ Postoperatively, it is common for patients to continue receiving high "neurosurgical doses" of corticosteroids, which, as proposed by Shay et al, ${ }^{41}$ may generate sufficient analgesia and euphoria to propagate the long-held belief that neurosurgery is painless.

\section{Dexamethasone}

Dexamethasone has been found to be particularly useful after the embolization of arteriovenous malformations or the coiling of aneurysms. ${ }^{42}$ The use of gabapentin in craniotomies was studied by Misra et $\mathrm{al}^{43}$ to evaluate the efficacy of dexamethasone and gabapentin in managing the incidence of vomiting and nausea within 24 hours postoperatively. Patients undergoing craniotomy were orally administered $600 \mathrm{mg}$ gabapen- tin premedication two hours prior to the induction of anesthesia. The patients were also intravenously infused with $4 \mathrm{mg}$ of dexamethasone on the morning of the procedure and every 8 hours following. The study reported a significant difference in the 24-hour incidence of nausea and the administration of antiemetics between the control placebo group and the group that was given dexamethasone and gabapentin. Conversely, the study found no difference in opioid consumption or postoperative pain scores between the two groups. As a result, despite any observable effect on the management of opioid consumption or postoperative pain scores, the administration of dexamethasone with gabapentin decreased the 24-hour incidence of postoperative vomiting and nausea in patients who underwent craniotomies. ${ }^{43}$

Although commonly given for surgical reasons, studies have shown that glucocorticoids ${ }^{44}$ and anticonvulsants ${ }^{45,46}$ can reduce the consumption of opioids and decrease perioperative pain, effectively serving as a multimodal analgesic approach. Türe et $\mathrm{al}^{38}$ demonstrated that gabapentinoids could be utilized as an element of the analgesic regimen for craniotomies. In this study, patients were administered either $1,200 \mathrm{mg} / \mathrm{d}$ of gabapentin or $300 \mathrm{mg} / \mathrm{d}$ of phenytoin at period intervals: a week prior to the procedure and the day of the procedure, postoperatively. A day prior to surgery, and postoperatively, the patients were also given dexamethasone. Following the induction of anesthesia, the patients were ventilated with oxygen and air. Anesthetics were maintained via propofol infusions and remifentanil titrated by processed electroencephalography. Postoperative pain was managed with patient-controlled analgesia (PCA) of morphine sulfate. The study found that patients in the phenytoin group emerged more quickly from anesthesia and were significantly less sedated during the initial several hours postoperatively than the gabapentin group, but it also found a small but significant reduction in pain in the gabapentin group relative to the phenytoin group within the initial hour post surgery. Furthermore, these patients were administered one-third less morphine during the 48-hour duration of the study. ${ }^{38}$

\section{Opioids}

Moderate-to-severe pain is most often treated with opioids following major surgery. However, in the case of neurosurgery, opioids appear to have a limited role. This appears to be due to a fear that opioids could adversely affect neurological examinations after neurosurgery, mask intracranial events, and cause sedation, miosis, and respiratory depression, increase intracranial pressure, and even cause cerebral edema. ${ }^{47}$

The severity and course of postoperative pain is affected by the choice of opioid medications administered during surgery. ${ }^{23}$ Hyperalgesia after intraoperative remifentanil use may cause hyperalgesia and increase analgesic requirements postoperatively. ${ }^{4,48}$

It has been shown that morphine is a better alternative for postoperative analgesia than codeine. Morphine is more effective than codeine beyond 60 minutes after recovery and requires fewer doses than codeine. ${ }^{49,50}$ Postoperative analgesic doses can be reduced by the administration of intraoperative morphine. $^{23}$

Narcotic drugs including oxycodone, codeine, propoxyphene, hydrocodone, and morphine have classically been utilized for the effective treatment of pain following craniotomies. ${ }^{51,52}$ This class of drugs functions by stimulating mu, kappa, and sigma subtype opioid receptors that are dispersed along the peripheral and central nervous system. The mu receptors are split into a number of subtypes including mu1 affecting supraspinal analgesia; mu2 that inhibits motility of the gastrointestinal tract and causes respiratory depression; and mu3 that acts on leukocytes and anti-inflammation. ${ }^{53,54}$ Administration of opioids can potentially have various side effects associated with stimulation of these receptors, which can thereby interrupt ambulation and recovery in patients, causing prolonged hospital stays. Due to the numerous adverse side effects (of particular concern, respiratory distress) of opioid analgesics, morphine or acetaminophen is commonly administered in conjunction on an as-needed basis. ${ }^{55}$ 
The effects of paracetamol and sufentanil on the treatment of pain management post craniotomy were assessed in a study by Hassani et $\mathrm{al}^{56}$ in 45 patients with brain tumors (American Society of Anesthesiologists Class [ASAI, II]). One group was administered a continuous infusion of sufentanil $(0.0015 \mu \mathrm{g} / \mathrm{kg} / \mathrm{min})$, the second group was given intermittent infusion of paracetamol ( $15 \mathrm{mg} / \mathrm{kg}$ every 6 hours) in $100 \mathrm{~mL}$ of normal saline within 15 minutes, and the third group was administered subcutaneous $5 \mathrm{mg}$ of morphine every 4 hours. The findings demonstrated that when hemodynamics, respiratory stability, and appropriate analgesia of sedation are maintained, sufentanil is an appropriate agent to address pain management post craniotomy. Patients in the group who were administered paracetamol reported the greatest pain score of visual analog scale and heart rate. This group also reported the lowest incidence of nausea and vomiting. The reduction in oxygen saturation was not observed within any of the groups. Rates of nausea and vomiting were highest in the patients in the morphine group. Thus, it was concluded that sufentanil yielded better results for diminishing nausea and vomiting, pain control, and hemodynamic stability relative to morphine, the most common drug of choice for pain management post craniotomy

\section{Nonsteroidal anti-inflammatory drugs and anti-inflammatory drugs (cyclooxygenase 2 inhibitors)}

Nonsteroidal anti-inflammatory drugs (NSAIDs) are another class of agents which appear to be effective for treating headaches, also seem to reliably reduce pain and morphine requirements by $25 \%-50 \%$ in a broad spectrum of postoperative settings, ${ }^{57,58}$ and decrease adverse effects following opioid administration. ${ }^{57}$ The use of NSAIDs in neurosurgery has been restricted due to their antiplatelet mechanism and apprehension regarding intracerebral hemorrhaging. While NSAIDs are efficient in offering analgesic effects (cyclooxygenase 2 [COX-2] isomer), they can also cause dysfunction of the platelets and elevate bleeding times (COX-1 isomer), which can be critically perilous in neurosurgical patients. The use of NSAIDs post craniotomy has for this reason been labeled as a major factor for bleeding perioperatively. ${ }^{59}$ A survey of adult neurosurgical units in the United Kingdom revealed no consensus in pain management in the UK and that $19 \%$ prescribed them on a regular basis. ${ }^{60}$

On the other hand, COX-2 inhibitors including parecoxib do not have antiplatelet properties and, therefore, are not as limited in terms of concern for bleeding complications. In fact, studies have shown that COX-2 inhibitors may reduce postoperative pain following craniotomies without increasing the risk of hemorrhage postoperatively. ${ }^{61}$ Therefore, should COX-2 inhibitors demonstrate effective analgesia with opioid-sparing properties, there would be great potential in their usage in neurosurgical procedures. The efficacy of COX-2 inhibitors as drugs for the management of postoperative pain has been well documented in orthopedic studies in patients who have undergone lumbar discectomies, knee and hip arthroplasty, and spinal fusions, ${ }^{62-64}$ as well as in patients who have undergone oral surgery and gynecological procedures. ${ }^{65-67}$ Despite these advantages, the consumption of COX-2 inhibitors has been restricted by numerous institutions due to the latest concerns of possible increases in risks of cardiovascular disease secondary to thrombotic events. ${ }^{68}$ In a prospective placebo-controlled, double-blind study, Jones et $\mathrm{al}^{69}$ assessed the efficacy of a single dose of $40 \mathrm{mg}$ parecoxib administered to 82 patients undergoing elective craniotomies. The results of the study showed that one intraoperative dose of parecoxib in patients who underwent craniotomy decreased pain scores at 6 hours and also reduced the administration of morphine 6-12 hours following the procedure, but generally did not have a significant effect on analgesia postoperatively.

This finding contrasted the study on NSAIDs for analgesia post craniotomy conducted by Tanskanen et al, ${ }^{70}$ which reported that regular administration of ketoprofen initiated an hour following craniotomy, relative to acetaminophen alone, reduced oxycodone PCA by $47 \%$ over the initial 24 hours.

\section{Acetaminophen}

\section{Acetaminophen is another available agent that is} used to manage mild-to-moderate pain

Paracetamol acetaminophen ( $N$-acetyl- $p$-aminophenol) inhibits central COXs to provide analgesia. It is devoid of the negative side effects associated with NSAID and opioid analgesics. Hassani et al studied the effects of sufentanil and paracetamol on postoperative pain control in patients who underwent craniotomy surgery and found that sufentanil provided better pain control and was associated with less nausea and vomiting; although patients who received paracetamol following surgery reported the least amount of nausea and vomiting, their quality of pain relief was considered poor. ${ }^{56}$

A new study is currently in progress that will assess the role of acetaminophen as an adjunct to the pain therapy for patients undergoing craniotomy. ${ }^{71}$ However, it does not exert any anti-inflammatory effects. ${ }^{72}$ Moreover, acetaminophen is already present in numerous analgesics administered orally for the treatment of postoperative pain, including 
vicodin, percocet, and darvocet. ${ }^{73}$ In contrast to aspirin and other NSAIDs, it causes analgesia centrally by activating descending serotonergic pathways and acting as a COX-3 inhibitor. ${ }^{74}$ In addition, its analgesic effects are likely to be due to its actions as a substance P and NMDA antagonist in the spinal cord and its cannabinoid agonistic effect. ${ }^{75}$

\section{Parecoxib}

COX is the enzyme that acts on arachidonic acid, and then triggers a reaction cascade that eventually forms prostaglandins, which are responsible for inflammation and pain. Drugs that selectively block COX-2 enzyme, called COX-2 inhibitors, have the advantage of anti-inflammation and analgesia without the opioid-associated sedation, nausea, or respiratory depression and do not cause platelet inhibition or increased bleeding risk seen with nonselective COX inhibitors. Thus, COX-2 inhibitors potentially can be effective analgesics for postoperative pain in neurosurgical patients. Parecoxib (not approved by the US Food and Drug Administration, but is available in Europe) has been a drug of interest since rofecoxib, another COX-2 inhibitor, was withdrawn from the market due to associated increased risk of myocardial infarction, which was demonstrated in the Vioxx Gastrointestinal Outcomes Research Trial. However, there is no evidence that suggests that adding parecoxib to a postoperative pain management regimen that includes scalp infiltration and intravenous (IV) morphine PCA has any additional benefits. ${ }^{50}$ There is still limited evidence to support parecoxib as an analgesic after craniotomy. ${ }^{69}$

\section{NMDA receptor antagonists}

Methadone and ketamine are common NMDA receptor antagonists that are used for the management of chronic pain. It has been shown in some studies that these drugs can effectively be used for preventive analgesia by decreasing the consumption of analgesics, acute postoperative pain, or both when administered with more traditional analgesic agents including NSAIDs and opioids perioperatively. ${ }^{76}$ NMDA receptor antagonists are believed to decrease pain by two mechanisms: reducing opioid tolerance and reducing central hypersensitivity. Nonetheless, the efficacy of NMDA antagonists in preventive analgesia has been ambiguous to date. ${ }^{77,78}$ The effect of ketamine on neurosurgical patients has not been evaluated due to its psychotropic effects. Conversely, methadone can serve as an essential multimodal analgesic, acting as both an NMDA receptor antagonist and an opioid. Of note, since it does affect the QT interval, electrocardiographic monitoring should be indicated at the start of and for chronic usage of the drug. Methadone has demonstrated success in delivering long-lasting analgesia and may restrict the tolerance development with concomitant use of NMDA receptor antagonist. ${ }^{79}$

\section{Tramadol}

Tramadol is an opioid analgesic, which acts as a weak $\mu$-receptor agonist as well as an inhibitor of serotonin and norepinephrine reuptake. Rahimi et $\mathrm{al}^{55}$ showed that the use of tramadol could produce better pain relief when used with narcotics and acetaminophen in addition to reducing the side effects of narcotics and decreasing costs associated with hospitalizations. ${ }^{55}$ Sudheer et $\mathrm{al}^{80}$ however, showed that tramadol administration resulted in more vomiting and retching, occurring in half of their study group, compared with $20 \%$ with morphine and $29 \%$ with codeine. ${ }^{80}$

Tramadol confers analgesic effects by inhibiting the reuptake of norepinephrine and serotonin, though the precise mechanism of its action is not yet entirely understood. Although it has been utilized successfully for the treatment of postoperative pain following cardiothoracic, orthopedic, and obstetric surgeries for some years, ${ }^{81-84}$ it is a comparatively novel analgesic that is not commonly used for the treatment of postoperative pain in neurosurgery. Due to the fact that it does not affect coagulation or platelet functionality, it is considered a safe agent for craniotomies. ${ }^{85}$ However, it weakly interacts with opioid receptors, which can cause certain analogous adverse side effects as opioids including dizziness, vomiting, nausea, and dry mouth. ${ }^{86}$

The cost analysis of tramadol was calculated, and it was concluded that the utilization of tramadol in the treatment of postoperative pain in craniotomy might potentially reduce the final cost of the procedure based on the analysis of length of stay and medication rates. Rahimi et al ${ }^{55}$ analyzed that the total cost of medications administered per patient was decreased by $\$ 32$ in a group of patients who received tramadol relative to a group that was given acetaminophen. In fact, even after adding tramadol to the analgesic regimen, a decreased amount of analgesic medications was administered to the patients at a lower total cost. The average length of stay for patients in the control group was 4.1 days, whereas the length of stay for patients in the tramadol group was decreased to 3.1 days - the study speculated that this reduction was attributable to the earlier tolerance to oral intake, fewer opioid adverse side effects, and more rapid ambulation in the tramadol group relative to the patients who received narcotics alone. Put into application, Rahimi et al ${ }^{55}$ argue that the use of this drug can potentially not only decrease 
total costs for patients undergoing craniotomy but also increase bed turnover rates in the hospitals for increased bed availability and more efficient institutional service.

This study also observed that the patients who were given tramadol in conjunction with opioid analgesics and acetaminophen reported reduced postoperative pain compared with those who did not receive tramadol. The narcotics group reported a visual analog scale pain score of 4.7 compared with a score of 3 in the tramadol group. There was no significant difference found in the amount of antiemetics administered between the two groups. ${ }^{55}$

Still, the beneficial effects of tramadol are not consistent with the findings throughout the study. In another study by Sudheer et al, ${ }^{80} 60$ craniotomy patients were assigned to receive $60 \mathrm{mg}$ of intramuscular codeine phosphate, or tramadol PCA or morphine PCA. Arterial carbon dioxide tension, pain score, and sedation were recorded at regular intervals, and patient satisfaction was reported at 24 hours. Although they found no significant differences in sedation or arterial carbon dioxide tension between the groups, patients reported greater satisfaction with morphine over tramadol or codeine $(P<0.001)$. The morphine group also produced significantly more effective analgesia than codeine at time points 4 hours, 12 hours, and 18 hours, and better analgesia than tramadol at all time points $(P<0.005)$. Furthermore, there was a greater incidence of nausea and vomiting reported in the tramadol group $(50 \%)$ than the codeine $(29 \%)$ or morphine $(20 \%)$ groups. ${ }^{80}$ It is also worth noting that some consider that codeine phosphate, a prodrug that is not entirely metabolized by a fraction of the population, is insufficient as a first-line agent in neurosurgery. ${ }^{87}$

\section{Dexmedetomidine}

Dexmedetomidine is a potent alpha2-adrenergic agonist that can provide sedation and analgesia with respiratory depression. Discomfort and agitation after neurosurgical procedures can be treated with dexmedetomidine. The administration of dexmedetomidine before the completion of major inpatient surgical procedures has been shown to significantly reduce opioid requirements. ${ }^{88}$

\section{Ropivacaine and lidocaine}

In the management of postoperative pain following craniotomies, practices have generally preferred infiltrations of the scalp with regional or local anesthesia that is similarly effective to or more beneficial than systemic drugs. ${ }^{89}$ A number of studies have observed that scalp infiltration with ropivicaine or bupivacaine reduced both the severity and incidence of postoperative pain. ${ }^{90-92}$ Preemptive administration of regional analgesia before the infliction of surgical trauma hypothetically attains blockage of peripheral pain stimuli, which is more beneficial than managing pain after it begins. This method also avoids the development of central hypersensitization via analgesic involvement. ${ }^{93,94}$

A study conducted by Song et $\mathrm{a}^{95}$ analyzed the differences in efficacy of analgesia in scalp infiltration with $0.5 \%$ ropivicaine and $1 \%$ lidocaine in addressing postoperative pain following craniotomy when separated into a group that received the infiltration presurgically and the other group post-procedurally. The severity of pain was recorded for 24 hours postoperatively and the score was based on a verbal numerical rating scale ranging from 0 (no pain) to 10 (most intense pain). Of the 52 patients who participated in the study, postoperative pain scores were significantly less in the group that received preemptive scalp infiltration of $0.5 \%$ ropivicaine and 1\% lidocaine within the first 6 hours post procedure. Furthermore, the average cumulative consumption of morphine was significantly lower in this group..$^{95}$ The complications that are associated with the administration of local anesthetics including increased wound drainage, infection, allergic reactions, and cardiovascular, local tissue, systemic, and central nervous system toxicity, as well as changes in wound healing were not found in this study. Thus, it was concluded that preemptive scalp infiltration using $1 \%$ lidocaine and $0.5 \%$ ropivicaine was significantly more efficacious to, before skin closure, infiltrations on analgesia postoperatively following craniotomies. ${ }^{95}$

It is proposed that preoperative administration of analgesia, including peripheral local anesthetic infiltration, is more effective than postoperative administration via numerous mechanisms. One school of thought is that the source of the most acute pain from surgical procedures is the anatomical trauma to the site of the local tissue and the following activation of the acute inflammatory response. ${ }^{96}$ Thus, the chemical mediators that are freed following injury lead to hyperexcitation of the neurons in the spinal cord and peripheral sensitization of primary sensory neurons. This in turn activates low threshold A-beta mechanoreceptors to initiate transmission of painful signals and causes central sensitization. ${ }^{77}$ This tissue-damage-initiated sensitization causes augmentation of pain signals..$^{97,98}$

\section{Scalp blocks: postoperative pain}

A scalp block refers to regional anesthesia of the nerves that supply sensation to the scalp. Combining general anesthesia with a scalp block provides the advantage of blunting 
hemodynamic response during particularly stimulating portions of neurosurgery (eg, head pinning and skin incision) as well as postoperative pain control.

There are six nerves, which can be blocked during a scalp block: supraorbital nerve, supratrochlear nerve, auriculotemporal nerve, zygomaticotemporal nerve, greater occipital nerve, and lesser occipital nerve.

Although uncommon, scalp blocks may be complicated by unintentional intravascular administration of local anesthetics and epinephrine which may lead to toxic levels leading to tachycardia and hypertension seizures and cardiac toxicity. ${ }^{99}$

Chaki et a ${ }^{100}$ used a mixture of lidocaine and ropivacaine for scalp blocks and local infiltration of the scalp. It gave satisfactory intraoperative pain control to the patients. Even though relatively large amounts of local anesthetics were administered, their blood concentration did not increase above half of the known toxic level. ${ }^{100}$ Generally, a scalp block is a safe technique and has been studied as a method for decreasing postoperative pain following neurosurgery. Song et $\mathrm{al}^{95}$ conducted a randomized trial to compare the analgesic efficacy of preemptive scalp infiltrations with $1 \%$ lidocaine and $0.5 \%$ ropivacaine on postoperative pain and found that these methods provided effective postoperative analgesia after craniotomy. ${ }^{95}$ Similarly, Bala et al ${ }^{101}$ demonstrated separately that surgical wound infiltration, before skin closure, with $0.5 \%$ bupivacaine and adrenaline, decreased the incidence and severity of postoperative pain in patients undergoing supratentorial craniotomy. ${ }^{101}$ In addition, scalp infiltration with either bupivacaine or ropivacaine has been shown to have a statistically significant effect on morphine consumption during the first two postoperative hours. ${ }^{91}$ Bloomfield et al ${ }^{102}$ studied whether scalp infiltration with bupivacaine during craniotomies reduces postoperative pain and hypertension. Patients who received a bupivacaine scalp block reported significantly less pain up to 1 hour after the postanaesthesia care unit admission; however, pain scores did not seem to correlate with heart rate or mean arterial pressure. ${ }^{102}$ Interestingly, Biswas and Bithal showed that preincisional scalp infiltration with $0.25 \%$ bupivacaine did not have any significant effect on post-craniotomy pain and analgesic requirement; however, bupivacaine may delay the requirement of the first analgesic dose. ${ }^{103}$

\section{PCA versus as needed}

One of the most safe and widely used methods of efficiently treating pain in children and adults is IV PCA. ${ }^{104-107}$ However, the safety and efficacy of this method have not widely been utilized or studied in patients who have undergone craniotomies. In a randomized controlled trial, Morad et $\mathrm{al}^{8}$ demonstrated that IV fentanyl PCA is more effective than conventional PRN therapy in the management of post-craniotomy pain. Significant differences between the patient groups who received analgesia intravenously via PCA or PRN were found $(P=0.015)$ - patients who received IV PCA reported lower pain scores relative to those in the PRN group within the 16 hours following admission into the North Carolina Central University $(2.53 \pm 1.96 ; 3.62 \pm 2.11$ $[P=0.039])$. There were no significant differences between the two groups in oxygen saturation, Glasgow Coma Scale scores, respiratory rate, or sedation sores. Importantly, there was no interference with the neurological examination and no reported increase in the deterioration neurologically, which further disproves the long-held belief that the administration of opioids may alter patients' neurological statuses to adversely affect outcomes. ${ }^{8}$

In the conventional PRN method, a patient needs to make a complaint regarding pain or request pain medication. The nurse attending the patient must then evaluate and respond to the patient, then prep and dispense the requested drug at a set time interval and dose. Commonly, the time interval and dosages are insufficient due to the prescriber's hesitance for usage due to the risk of opioid-induced adverse side effects, lack of experience with opioid pharmacology, unsubstantiated apprehension of the development of addiction to the drug, and a lack of appreciation of the pain being experienced by the patient. ${ }^{108}$ Due to this sequence of required steps, there is, even with optimal systematic efficiency, a delay time between the initial request for a drug and its administration. Morad et al ${ }^{8}$ therefore suggest that it is perhaps not entirely surprising that they found that IV fentanyl PCA was more effective than the administration of PRN opioid.

On the other hand, personal patient-by-patient-dependent analgesic management is managed by the immediate response and assorted dosing patterns that the PCA device allows. Commonly, patients receive $<50 \%$ of the permitted total PRN prescription. ${ }^{109,110}$

\section{Conclusion}

There seem to be impediments to control pain after neurosurgery due to several reasons leading to the undertreatment of pain after neurosurgery. ${ }^{47}$

These impediments range from fear that opioids could interfere with postoperative outcomes and neurological examinations to poor assessment of pain postoperatively to inconsistent data after neurosurgical procedures in the studies regarding pain control in this population. 
The adequate management of pain post-procedurally is critical for addressing the distress experienced by the patients, because inadequate postoperative analgesia may in fact be associated with a greater incidence of complications postprocedurally and increase the duration of hospital stay, and thereby ultimately raise health expenses. ${ }^{111}$ Furthermore, it has been demonstrated that severe pain experienced postoperatively can potentially lead to arterial hypertension via sympathetic stimulation, which increases the risk of causing secondary hemorrhage intracranially. ${ }^{12}$ In neurosurgical procedures, the incidence of pain is associated with surgical site. The highest incidence of postoperative pain after craniotomies occur after subtemporal and suboccipital approaches, ${ }^{17}$ whereas patients who undergo frontal craniotomy experience less pain and require less opioid analgesics. ${ }^{18}$

Craniotomy pain occurs as a consequence of injury to the cutaneous nerves that supply sensation to the scalp, the underlying tissues, or from manipulation of the dura mater.

There are conflicting conclusions derived from the dearth of evidence-based reports leading to inconsistent practices in the management of perioperative neurosurgical pain. Postoperative pain management after neurosurgical procedures is complex with the employment of multimodal strategies to decrease untoward side effects and achieve optimum pain control. Improved pain assessment, employment of multimodal analgesic, and increased research with randomized clinical trials are warranted in this area to improve the quality of current analgesic strategies for neurosurgical patients in the perioperative period to achieve adequate analgesia and consensus in the standardization of pain control in this population.

\section{Disclosure}

The authors report no conflicts of interest in this work.

\section{References}

1. Hansen MS, Brennum J, Moltke FB, Dahl JB. Pain treatment after craniotomy: where is the (procedure-specific) evidence? A qualitative systematic review. Eur J Anaesthesiol. 2011;28(12):821-829.

2. Hansen MS, Brennum J, Moltke FB, Dahl JB. Suboptimal pain treatment after craniotomy. Dan Med J. 2013;60(2):A4569.

3. Quiney N, Cooper R, Stoneham M, Walters F. Pain after craniotomy. A time for reappraisal? Br J Neurosurg. 1996;10(3):295-299.

4. Flexman AM, Ng JL, Gelb AW. Acute and chronic pain following craniotomy. Curr Opin Anaesthesiol. 2010;23(5):551-557.

5. Gottschalk A, Berkow LC, Stevens RD, et al. Prospective evaluation of pain and analgesic use following major elective intracranial surgery. J Neurosurg. 2007;106(2):210-216.

6. Gottschalk A, Yaster M. The perioperative management of pain from intracranial surgery. Neurocrit Care. 2009;10(3):387-402.

7. Morad A, Winters B, Stevens R, et al. The efficacy of intravenous patientcontrolled analgesia after intracranial surgery of the posterior fossa: a prospective, randomized controlled trial. Anesth Analg. 2012;114(2): 416-423.
8. Morad AH, Winters BD, Yaster M, et al. Efficacy of intravenous patient-controlled analgesia after supratentorial intracranial surgery: a prospective randomized controlled trial. Clinical article. J Neurosurg. 2009;111(2):343-350.

9. Ostermann ME, Keenan SP, Seiferling RA, Sibbald WJ. Sedation in the intensive care unit: a systematic review. JAMA. 2000;283(11): 1451-1459.

10. Cold GE, Felding M. Even small doses of morphine might provoke "luxury perfusion" in the postoperative period after craniotomy. Neurosurgery. 1993;32(2):327.

11. Maxwell LG, Buckley GM, Kudchadkar SR, et al. Pain management following major intracranial surgery in pediatric patients: a prospective cohort study in three academic children's hospitals. Paediatr Anaesth. 2014;24(11):1132-1140.

12. Basali A, Mascha EJ, Kalfas I, Schubert A. Relation between perioperative hypertension and intracranial hemorrhage after craniotomy. Anesthesiology. 2000;93(1):48-54.

13. de Gray LC, Matta BF. Acute and chronic pain following craniotomy: a review. Anaesthesia. 2005;60(7):693-704.

14. Talke PO, Gelb AW. Postcraniotomy pain remains a real headache! Eur J Anaesthesiol. 2005;22(5):325-327.

15. Dahl JB, Kehlet H. Preventive analgesia. Curr Opin Anaesthesiol. 2011;24(3):331-338.

16. Mordhorst C, Latz B, Kerz T, et al. Prospective assessment of postoperative pain after craniotomy. J Neurosurg Anesthesiol. 2010;22(3):202-206.

17. De Benedittis G, Lorenzetti A, Migliore M, Spagnoli D, Tiberio F, Villani RM. Postoperative pain in neurosurgery: a pilot study in brain surgery. Neurosurgery. 1996;38(3):466-469. [discussion 469-470].

18. Thibault M, Girard F, Moumdjian R, Chouinard P, Boudreault D, Ruel M. Craniotomy site influences postoperative pain following neurosurgical procedures: a retrospective study. Can J Anaesth. 2007;54(7):544-548.

19. Comway C. Neurological Anaesthesia - A Practice of Anesthesia. 5th ed. London: Lloyd Luke; 1984.

20. Gantenbein AR, Sarikaya H, Riederer F, Goadsby PJ. Postoperative hemicrania continua-like headache - a case series. J Headache Pain. 2015;16:526.

21. Kim YD, Park JH, Yang SH, et al. Pain assessment in brain tumor patients after elective craniotomy. Brain Tumor Res Treat. 2013;1(1):24-27.

22. de Gray LC, Matta BF. Acute and chronic pain following craniotomy: a review. Anaesthesia. 2010;23(5):551-557.

23. Ayrian E, Kaye AD, Varner CL, et al. Effects of anesthetic management on early postoperative recovery, hemodynamics and pain after supratentorial craniotomy. J Clin Med Res. 2015;7(10):731-741.

24. Loeser JD, Bonica JJ. Bonica's Management of Pain. Philadelphia: Lippincott Williams and Wilkins; 2001.

25. Gee JR, Ishaq Y, Vijayan N. Postcraniotomy headache. Headache. 2003;43(3):276-278.

26. Vijayan N. Postoperative headache in acoustic neuroma. Headache. 1995;35(2):98-100.

27. Dunbar PJ, Visco E, Lam AM. Craniotomy procedures are associated with less analgesic requirements than other surgical procedures. Anesth Analg. 1999;88(2):335-340.

28. Gottschalk A. Craniotomy pain: trying to do better. Anesth Analg. 2009;109(5):1379-1381.

29. Batoz H, Verdonck O, Pellerin C, Roux G, Maurette P. The analgesic properties of scalp infiltrations with ropivacaine after intracranial tumoral resection. Anesth Analg. 2009;109(1):240-244.

30. Dahl J, Mathiesen O, Møiniche S. 'Protective premedication': an option with gabapentin and related drugs? A review of gabapentin and pregabalin in in the treatment of post-operative pain. Acta Anaesthesiol Scand. 2004;48(9):1130-1136.

31. Gidal BE. New and emerging treatment options for neuropathic pain. Am J Manag Care. 2006;12(9 suppl):S269-S278.

32. Elwes RDC, Binnie CD. Clinical pharmacokinetics of newer antiepileptic drugs. Clin Pharmacokinet. 1996;30(6):403-415. 
33. Markman JD, Dworkin RH. Ion channel targets and treatment efficacy in neuropathic pain. J Pain. 2006;7(1 suppl 1):S38-S47.

34. Chang CY, Challa CK, Shah J, Eloy JD. Gabapentin in acute postoperative pain management. Biomed Res Int. 2014;2014:631756.

35. Maneuf YP, Gonzalez MI, Sutton KS, Chung FZ, Pinnock RD, Lee K. Cellular and molecular action of the putative GABA-mimetic, gabapentin. Cell Mol Life Sci. 2003;60(4):742-750.

36. Taylor CP, Gee NS, Su TZ, et al. A summary of mechanistic hypotheses of gabapentin pharmacology. Epilepsy Res. 1998;29(3):233-249.

37. Sills GJ. Not another gabapentin mechanism! Epilepsy Curr. 2005;5(2):75-77.

38. Türe H, Sayin M, Karlikaya G, Bingol CA, Aykac B, Türe U. The analgesic effect of gabapentin as a prophylactic anticonvulsant drug on postcraniotomy pain: a prospective randomized study. Anesth Analg. 2009;109(5):1625-1631.

39. Rhen T, Cidlowski JA. Antiinflammatory action of glucocorticoids - new mechanisms for old drugs. N Engl J Med. 2005;353(16):1711-1723.

40. Apfel CC, Korttila K, Abdalla M, et al; IMPACT Investigators. A factorial trial of six interventions for the prevention of postoperative nausea and vomiting. N Engl J Med. 2004;350(24):2441-2451.

41. Shay JE, Kattail D, Morad A, Yaster M. The postoperative management of pain from intracranial surgery in pediatric neurosurgical patients. Paediatr Anaesth. 2014;24(7):724-733.

42. Kundra S, Mahendru V, Gupta V, Choudhary AK. Principles of neuroanesthesia in aneurysmal subarachnoid hemorrhage. J Anaesthesiol Clin Pharmacol. 2014;30(3):328-337.

43. Misra S, Parthasarathi G, Vilanilam GC. The effect of gabapentin premedication on postoperative nausea, vomiting, and pain in patients on preoperative dexamethasone undergoing craniotomy for intracranial tumors. J Neurosurg Anesthesiol. 2013;25(4):386-391.

44. Kardash KJ, Sarrazin F, Tessler MJ, Velly AM. Single-dose dexamethasone reduces dynamic pain after total hip arthroplasty. Anesth Analg. 2008;106(4):1253-1257. [table of contents].

45. Tiippana EM, Hamunen K, Kontinen VK, Kalso E. Do surgical patients benefit from perioperative gabapentin/pregabalin? A systematic review of efficacy and safety. Anesth Analg. 2007;104(6):1545-1556. [table of contents].

46. Wiffen P, Collins S, McQuay H, Carroll D, Jadad A, Moore A. Anticonvulsant drugs for acute and chronic pain. Cochrane Database Syst Rev. 2005;(3):CD001133.

47. Gottschalk A, Yaster M. Pain management after craniotomy. Neurosurg $Q$. 2007;17(1):64-73.

48. Guy J, Hindman BJ, Baker KZ, et al. Comparison of remifentanil and fentanyl in patients undergoing craniotomy for supratentorial spaceoccupying lesions. Anesthesiology. 1997;86(3):514-524.

49. Verchère E, Grenier B, Mesli A, Siao D, Sesay M, Maurette P. Postoperative pain management after supratentorial craniotomy. J Neurosurg Anesthesiol. 2002;14(2):96-101.

50. Williams DL, Pemberton E, Leslie K. Effect of intravenous parecoxib on post-craniotomy pain. Br J Anaesth. 2011;107(3):398-403.

51. Herbert C. Use of morphine for pain after intracranial surgery. Prof Nurse. 2001;16(4):1029-1033.

52. Stoneham MD, Cooper R, Quiney NF, Walters FJ. Pain following craniotomy: a preliminary study comparing PCA morphine with intramuscular codeine phosphate. Anaesthesia. 1996;51(12):1176-1178.

53. Zhang AZ, Pasternak GW. Ontogeny of opioid pharmacology and receptors: high and low affinity site differences. Eur J Pharmacol. 1981;73(1):29-40.

54. Pasternak GW. Molecular biology of opioid analgesia. J Pain Symptom Manage. 2005;29(5 suppl):S2-S9.

55. Rahimi SY, Alleyne CH Jr, Vernier E, Witcher MR, Vender JR. Postoperative pain management with tramadol after craniotomy: evaluation and cost analysis: clinical article. J Neurosurg. 2010;112(2): 268-272.

56. Hassani E, Mahoori A, Sane S, Tolumehr A. Comparison the effects of paracetamol with sufentanil infusion on postoperative pain control after craniotomy in patients with brain tumor. Adv Biomed Res. 2015;4:64.
57. Schug SA, Manopas A. Update on the role of non-opioids for postoperative pain treatment. Best Pract Res Clin Anaesthesiol. 2007;21(1):15-30.

58. Gan TJ, Joshi GP, Zhao SZ, Hanna DB, Cheung RY, Chen C. Presurgical intravenous parecoxib sodium and follow-up oral valdecoxib for pain management after laparoscopic cholecystectomy surgery reduces opioid requirements and opioid-related adverse effects. Acta Anaesthesiol Scand. 2004;48(9):1194-1207.

59. Palmer JD, Sparrow OC, Iannotti F. Postoperative hematoma: a 5-year survey and identification of avoidable risk factors. Neurosurgery. 1994;35(6): 1061.

60. Kotak D, Cheserem B, Solth A. A survey of post-craniotomy analgesia in British neurosurgical centres: time for perceptions and prescribing to change? Br J Neurosurg. 2009;23(5):538-542.

61. Rahimi SY, Vender JR, Macomson SD, French A, Smith JR, Alleyne CH Jr. Postoperative pain management after craniotomy: evaluation and cost analysis. Neurosurgery. 2006;59(4):852-857.

62. Bekker A, Cooper PR, Frempong-Boadu A, Babu R, Errico T, Lebovits A. Evaluation of preoperative administration of the cyclooxygenase-2 inhibitor rofecoxib for the treatment of postoperative pain after lumbar disc surgery. Neurosurgery. 2002;50(5):1053-1057. [discussion 1057-1058].

63. Gimbel JS, Brugger A, Zhao W, Verburg KM, Geis GS. Efficacy and tolerability of celecoxib versus hydrocodone/acetaminophen in the treatment of pain after ambulatory orthopedic surgery in adults. Clin Ther. 2001;23(2):228-241.

64. Hubbard RC, Naumann TM, Traylor L, Dhadda S. Parecoxib sodium has opioid-sparing effects in patients undergoing total knee arthroplasty under spinal anaesthesia. Br J Anaesth. 2003;90(2):166-172.

65. Karamanloglu B, Turan A, Memis D, Türe M. Preoperative oral rofecoxib reduces postoperative pain and tramadol consumption in patients after abdominal hysterectomy. Anesth Analg. 2004;98(4):1039.

66. Mehlisch DR, Desjardins PJ, Daniels S, Hubbard RC. Single doses of parecoxib sodium intravenously are as effective as ketorolac in reducing pain after oral surgery. J Oral Maxillofac Surg. 2003;61(9):1030-1037.

67. Tang J, Li S, White PF, et al. Effect of parecoxib, a novel intravenous cyclooxygenase type- 2 inhibitor, on the postoperative opioid requirement and quality of pain control. Anesthesiology. 2002;96(6):1305-1309.

68. Pawlosky N. Cardiovascular risk: are all NSAIDs alike? Can Pharm J. 2013;146(2):80-83.

69. Jones SJ, Cormack J, Murphy MA, Scott DA. Parecoxib for analgesia after craniotomy. Br J Anaesth. 2009;102(1):76-79.

70. Tanskanen P, Kyttä J, Randell T. Patient-controlled analgesia with oxycodone in the treatment of postcraniotomy pain. Acta Anaesthesiol Scand. 1999;43(1):42-45.

71. Haldar R, Kaushal A, Gupta D, Srivastava S, Singh PK. Pain following craniotomy: Reassessment of the available options. Biomed Res Int. 2015;2015:509164.

72. Howland RD. Nonsteroidal anti-inflammatory drugs. In: Mycek MJ, Harvey RA, Champe PC, editors. Lippincott's Illustrated Reviews: Pharmacology. 2nd ed. Philadelphia: Lippincott Williams and Wilkins; 2000:403-406.

73. Kaye AM, Kaye AD, Lofton EC. Basic concepts in opioid prescribing and current concepts of opioid-mediated effects on driving. Ochsner $J$. 2013;13(4):525-532.

74. Anderson BJ. Paracetamol (acetaminophen): mechanisms of action. Paediatr Anaesth. 2008;18(10):915-921.

75. Bertolini A, Ferrari A, Ottani A, Guerzoni S, Tacchi R, Leone S. Paracetamol: new vistas of an old drug. CNS Drug Rev. 2006; 12(3-4):250-275.

76. McCartney CJL, Sinha A, Katz J. A qualitative systematic review of the role of N-methyl-D-aspartate receptor antagonists in preventive analgesia. Anesth Analg. 2004;98(5):1385-1400. [table of contents].

77. Pogatzki-Zahn EM, Zahn PK, Brennan TJ. Postoperative pain - clinical implications of basic research. Best Pract Res Clin Anaesthesiol. 2007;21(1):3-13. 
78. Pogatzki-Zahn EM, Zahn PK. From preemptive to preventive analgesia. Curr Opin Anaesthesiol. 2006;19(5):551-555.

79. Salehi M, Zargar A, Ramezani MA. Effects of dextromethorphan on reducing methadone dosage in opium addicts undergoing methadone maintenance therapy: a double blind randomized clinical trial. $J$ Res Med Sci. 2011;16(10):1354-1360.

80. Sudheer PS, Logan SW, Terblanche C, Ateleanu B, Hall JE. Comparison of the analgesic efficacy and respiratory effects of morphine, tramadol and codeine after craniotomy. Anaesthesia. 2007;62(6):555-560.

81. Bourne MH, Rosenthal NR, Xiang J, Jordan D, Kamin M. Tramadol/ acetaminophen tablets in the treatment of postsurgical orthopedic pain. Am J Orthop. 2005;34(12):592-597.

82. But AK, Erdil F, Yucel A, Gedik E, Durmus M, Ersoy MO. The effects of single-dose tramadol on post-operative pain and morphine requirements after coronary artery bypass surgery. Acta Anaesthesiol Scand. 2007;51(5):601-606.

83. Kocabas S, Karaman S, Uysallar E, Firat V. The use of tramadol and morphine for pain relief after abdominal hysterectomy. Clin Exp Obstet Gynecol. 2005;32(1):45-48.

84. Memis D, Turan A, Karamanlioglu B, Tükenmez B, Pamukçu Z. The effect of tramadol or clonidine added to intraperitoneal bupivacaine on postoperative pain in total abdominal hysterectomy. J Opioid Manag. 2005;1(2):77-82.

85. Ferber J, Juniewicz H, Głogowska E, Wroński J, Abraszko R, Mierzwa J. Tramadol for postoperative analgesia in intracranial surgery. Its effect on ICP and CPP. Neurol Neurochir Pol. 2000;34(6 suppl):70-79.

86. Leppert W, Łuczak J. The role of tramadol in cancer pain treatment a review. Support Care Cancer. 2004;13(1):5-17.

87. Goldsack C, Scuplak SM, Smith M. A double-blind comparison of codeine and morphine for postoperative analgesia following intracranial surgery. Anaesthesia. 1996;51(11):1029-1032.

88. Unlugenc H, Gunduz M, Guler T, Yagmur O, Isik G. The effect of pre-anaesthetic administration of intravenous dexmedetomidine on postoperative pain in patients receiving patient-controlled morphine. Eur J Anaesthesiol. 2005;22(5):386-391.

89. Guilfoyle MR, Helmy A, Duane D, Hutchinson PJ. Regional scalp block for postcraniotomy analgesia: a systematic review and meta-analysis. Anesth Analg. 2013;116(5):1093-1102.

90. Nguyen A, Girard F, Boudreault D, et al. Scalp nerve blocks decrease the severity of pain after craniotomy. Anesth Analg. 2001;93(5): 1272-1276.

91. Law-Koune JD, Szekely B, Fermanian C, Peuch C, Liu N, Fischler M. Scalp infiltration with bupivacaine plus epinephrine or plain ropivacaine reduces postoperative pain after supratentorial craniotomy. J Neurosurg Anesthesiol. 2005;17(3):139-143.

92. Saringcarinkul A, Boonsri S. Effect of scalp infiltration on postoperative pain relief in elective supratentorial craniotomy with $0.5 \%$ bupivacaine with adrenaline 1: 400,000. J Med Assoc Thai. 2008;91(10):1518.

93. Johnson SM, Saint John BE, Dine AP. Local anesthetics as antimicrobial agents: a review. Surg Infect. 2008;9(2):205-213.

94. Katz J, Cohen L, Schmid R, Chan VW, Wowk A. Postoperative morphine use and hyperalgesia are reduced by preoperative but not intraoperative epidural analgesia: implications for preemptive analgesia and the prevention of central sensitization. Anesthesiology. 2003;98(6):1449-1460.
95. Song J, Li L, Yu P, Gao T, Liu K. Preemptive scalp infiltration with $0.5 \%$ ropivacaine and $1 \%$ lidocaine reduces postoperative pain after craniotomy. Acta Neurochir. 2015;157(6):993-998.

96. Kaufman E, Epstein JB, Gorsky M, Jackson DL, Kadari A. Preemptive analgesia and local anesthesia as a supplement to general anesthesia: a review. Anesth Prog. 2005;52(1):29-38.

97. Coughlin SM, Karanicolas PJ, Emmerton-Coughlin HM, Kanbur B, Kanbur S, Colquhoun PH. Better late than never? Impact of local analgesia timing on postoperative pain in laparoscopic surgery: a systematic review and metaanalysis. Surg Endosc. 2010;24(12):3167-3176.

98. Woolf CJ, Chong MS. Preemptive analgesia-treating postoperative pain by preventing the establishment of central sensitization. Anesth Analg. 1993;77(2):362.

99. Chakrabarti R, Ghazanwy M, Tewari A. Anesthetic challenges for deep brain stimulation: a systematic approach. $N \mathrm{Am} \mathrm{J} \mathrm{Med} \mathrm{Sci.}$ 2014;6(8):359-369.

100. Chaki T, Sugino S, Janicki PK, et al. Efficacy and safety of a lidocaine and ropivacaine mixture for scalp nerve block and local infiltration anesthesia in patients undergoing awake craniotomy. $J$ Neurosurg Anesthesiol. 2016;28(1):1-5.

101. Bala I, Gupta B, Bhardwaj N, Ghai B, Khosla VK. Effect of scalp block on postoperative pain relief in craniotomy patients. Anaesth Intensive Care. 2006;34(2):224-227.

102. Bloomfield EL, Schubert A, Secic M, Barnett G, Shutway F, Ebrahim ZY. The influence of scalp infiltration with bupivacaine on hemodynamics and postoperative pain in adult patients undergoing craniotomy. Anesth Analg. 1998;87(3):579-582.

103. Biswas BK, Bithal PK. Preincision $0.25 \%$ bupivacaine scalp infiltration and postcraniotomy pain: a randomized double-blind, placebocontrolled study. J Neurosurg Anesthesiol. 2003;15(3):234-239.

104. Berde CB, Lehn BM, Yee JD, Sethna NF, Russo D. Patient-controlled analgesia in children and adolescents: a randomized, prospective comparison with intramuscular administration of morphine for postoperative analgesia. J Pediatr. 1991;118(3):460-466.

105. Hudcova J, McNicol E, Quah C, Lau J, Carr DB. Patient controlled opioid analgesia versus conventional opioid analgesia for postoperative pain. Cochrane Database Syst Rev. 2006;(4):CD003348.

106. Smythe M. Patient-controlled analgesia: a review. Pharmacotherapy. 1992;12(2):132-143.

107. Yaster M, Billett C, Monitto C. Intravenous patient controlled analgesia. In:Yaster M, Krane EJ, Kaplan RF, editors. Pediatric Pain Management and Sedation Handbook. St Louis: Mosby; 1997:89-112.

108. Roberts G. A review of the efficacy and safety of opioid analgesics post-craniotomy. Nurs Crit Care. 2004;9(6):277-283.

109. de Rond ME, de Wit R, van Dam FS, Muller MJ. A pain monitoring program for nurses: effect on the administration of analgesics. Pain. 2000;89(1):25-38.

110. McCaffery M, Pasero C, Ferrell BR. Nurses' decisions about opioid dose. Am J Nurs. 2007;107(12):35-39.

111. Leslie K, Troedel S, Irwin K, et al. Quality of recovery from anesthesia in neurosurgical patients. Anesthesiology. 2003;99(5):1158-1165.

Journal of Pain Research

\section{Publish your work in this journal}

The Journal of Pain Research is an international, peer-reviewed, open access, online journal that welcomes laboratory and clinical findings in the fields of pain research and the prevention and management of pain. Original research, reviews, symposium reports, hypothesis formation and commentaries are all considered for publication.

The manuscript management system is completely online and includes a very quick and fair peer-review system, which is all easy to use. Visit http://www.dovepress.com/testimonials.php to read real quotes from published authors.

\section{Dovepress}

Submit your manuscript here: http://www.dovepress.com/journal-of-pain-research-journal 